\title{
Model Interprestasi Alquran dalam Pendekatan Tafsir Kontekstual Abdullah Saeed
}

\section{Thoriq Aziz Jayana}

Pascasarjana UIN Maulana Malik Ibrahim Malang

azizjthoriq@yahoo.com

DOI: $10.29240 /$ alquds.v3i1. 612

Submitted: 2018-11-29| Revised: 2019-04-16 | Accepted: 2019-04-25

\begin{abstract}
This paper examines Abdullah Saeed's thought about the method of interpreting the Quran. While the method used in this paper is library research. In this paper, we will discuss from Saeed's thought which shows that he should consider his thinking in Islamic Studies, the initial basis for contextual interpretation, what principles must be held in interpreting the Koran, and more importantly the interpretation model offered by Saeed. In this paper we can summarize some points, that Saeed's thought as a refiner to Fazlur Rahman's hermeneutic double movement, seeks to provide an alternative in interpreting the Quran in the 21 st century with a 'contextual interpretation' that is more flexible and takes into account the context of the revelation period, especially in ethically-charged verses legal. By calling himself a 'contextualist', Saeed formulated the steps of interpretation as a methodology that is interesting to study in the present, so that the Quran can still 'live' in all times; past, now and later.
\end{abstract}

Keywords: methodology, contextual interpretation, ethico-legal

\begin{abstract}
Abstrak. Tulisan ini bertujuan mengkaji pemikiran Abdullah Saeed tentang metode penafsiran Alquran. Sedangkan metode yang digunakan dalam kajian ini ialah library research (penelitian kepustakaan). Dalam tulisan ini akan membahas pemikiran Saeed yang menunjukkan bahwa ia patut dipertimangkan pemikirannya dalam Studi Islam, pijakan awal mengapa harus dilakukan interpretasi kontekstual, prinsip-prinsip apa saja yang harus dipegang dalam menginterpretasikan Alquran, serta yang lebih penting ialah model interpretasi yang ditawarkan oleh Saeed. Dalam tulisan ini pula dapat disimpulkan beberapa point, diantaranya bahwa pemikiran Saeed sebagai penyempurna dari hermeneutika double movement-nya Fazlur Rahman, Saeed juga berupaya memberikan sebuah alternatif dalam menafsirkan Alqurandi abad 21 ini dengan sebuah 'interpretasi kontekstual' yang lebih fleksibel dan memperhatikan konteks masa kewahyuan, terutama pada ayat-ayat yang bermuatan ethico-legal. Dengan menyebut dirinya sebagai 'kontekstualis', Saeed mampu merumuskan langkah-langkah interpretasi sebagai sebuah metodologi yang menarik untuk dikaji da dijadikan khazanah keilmuan pada masa sekarang ini, sehingga Alquran tetap dapat 'hidup' pada seluruh zaman; dulu, sekarang dan nanti.
\end{abstract}


38 | AL QUDS : Jurnal Studi Alquran dan Hadis vol. 3, no 1, 2019

Kata Kunci: Metodologi, interpretasi kontekstual, ethico-legal

\section{Pendahuluan}

Alquran sebagai pedoman hidup umat Islam tentu menjadi suatu hal yang urgen untuk diamalkan dan memberikan solusi dalam kehidupan. Meski Alquranditurunkan dengan berbahasa Arab dan membawa setting sosio-culture masyarakat Arab pada 14 abad yang lalu, namun Alquran haruslah tetap menjadi jalan keluar dalam berbagai permasalahan pada masa sekarang dan di mana pun dia berada. Sehingga semua sepakat bahwa Alquranharuslah shalih fi kulli zaman wa makan.

Inilah yang kemudian menjadi permasalahan dan menimbulkan keresahan intelektual, di satu sisi ada individu atau sekelompok orang yang bersikukuh hingga membuat umat terkungkung dengan makna literal-tekstual Alquran yang membuatnya kaku untuk zaman modern saat ini, sehingga Alquran (hukum Islam) stagnan dan tidak berdaya dialog dengan realitas. ${ }^{1}$ Dan di sisi lain adanya suatu dilema bagi umat Islam bagaimana cara membawa makna lokal Alquranyang berhostoris Arab pada masa lalu tersebut ke dunia luar dengan kondisi dan masa yang jauh berbeda dengan masa kini, agar Alquran tetap 'hidup' dalam segala situasi dan kondisi, seyogyanya haruslah dicarikan metode penemuan makna tersembunyi dari teks tersebut.

Hal inilah kemudian yang memeras intelektualisme para cendekiawan muslim untuk mencarikan sebuah jawaban atas keresahan dan dilema tersebut. Sebutlah Fazlur Rahman dengan hermeneutika double movement-nya, Hasan Hanafi dengan hermeneutika sosial-nya (al-manhaj al-ijtima'i fi at-tafsyri), Nasr Hamid Abu Zayd dengan hermeneutika inklusif-nya, Husein Muhammad dengan bermeneutika feminis-nya, Muhammad Syahrur dengan teori the limit-nya, Abdullah Saeed dengan hermeneutika kontekstual-nya (contextual approach), dan lain sebagainya. ${ }^{2}$ Hal itu dilakukan tidak lain sebagai sebuah upaya untuk

1 Tholhatul Choir, Islam Dalam Berbagai Pembacaan Kontemporer (Yogyakarta: Pustaka Pelajar, 2009), 525.

${ }^{2}$ Istilah hermeneutika sendiri berasal dari bahasa Yunani yakni hermeneuein yang bermakna 'menjelaskan' (explain) kemudian kata tersebut diserap dalam bahasa Inggris menjadi hermeneutics, yang oleh Schleiermacher-dikutip dari Jean Grondin-didefinisikan sebagai the art of understanding rightly another man's language, particularly bis written language (seni memahami secara benar bahasa orang, khususnya bahasa tulisan). Lihat: Jean Grondin, Introduction to Philosophical Hermeneutics (New Haven: Yale University Press, 1991), 104. Dimana dalam menggunakan hermeneutika tidak semudah yang dibayangkan, sebab seorang penafsir harus 'mengalmai 
mengungkap sebuah makna utuh yang ingin disampaikan oleh Alquran kepada semua umat Islam. Kelompok intelektual seperti di atas inilah yang kemudian disebut oleh Saeed sebagai the progressive-ijtihadist, yakni para cendekiawan modern yang berupaya menafsir ulang ajaran-ajaran agama, hingga dapat menjawab kompleksitas permalsahan saat ini. ${ }^{3}$

Berkaitan dengan hal tersebut, menarik kiranya bagi kita untuk mengkaji salah satu pemikiran cendekiawan muslim diatas di abad 21 ini yang menyebut dirinya sebagai kontekstualis dan penyempurna dari double movement-nya Fazlur Rahman, yakni Abdullah Saeed. ${ }^{4}$ Dimana Saeed berupaya mensistematisasikan pemikiran Rahman yang kurang dipahami oleh kalangan umum secara metodologis yang terperinci. Terutama pemikiran Saeed yang tertuang dalam bukunya yang berjudul Interpreting the Quran: Towards a Contemporary Approach, yang memuat tentang metodologi tafsir yang ditawarkan olehnya.

Fazlur Rahman dengan teori double movement (gerak ganda) berpandangan bahwa dalam menginterpretasikan (menafsirkan) Alquran, seorang penafsir haruslah melakukan 'gerak ganda'. Gerakan pertama ialah seorang penafsir harus mampu menyelinap ke masa lalu, memahami konteks di mana Alquranditurunkan. Setelah itu, gerak kedua ialah bagaimana seorang penafsir harus mengkontekstualisasikan 'gerak pertama' tersebut dan mengkonstruksi pemahaman ke masa kini. ${ }^{5}$ Namun, sekali lagi, bahwa apa yang diupayakan Rahman dengan hermeneutikanya tersebut kurang memberikan pemahaman secara konkrit bagi kalangan umum atau pemula. Sehingga berawal dari gagasan inilah, dimana double movement Rahman yang dipandanganya mampu memberikan

kembali' (wiedererleben), 'memasuki kesadaran' (einleben), dan memahami konteks dimana teks itu diturunkan, dan 'menyelami' (sich bineinversetzen) pemikiran penyusun teks/penerima teks. Sehingga pesan yang ingin disampaikan dalam sebuah teks tersebut benar-benar tersampaikan secara utuh.

${ }^{3}$ Abdullah Saeed, Islamic Thought: An Introduction (New York: Routledge, 2006), 142. Hal ini tidak juga disampaikan oleh Tariq Ramadan yang memberikan kategorisasi kepada intelektual muslim yang memasukkan kelompok yang disebut oleh Saeed sebagai the progressive-ijtihadistdengan istilah liberal or rational reformism. Lihat: Tariq Ramadan, Western Muslims and The Future of Islam (New York: Oxford University Press, 2004), 28.

${ }^{4}$ Saeed menyebut dirinya sebagai contexstualist untuk merujuk kepada pemikir Islam yang memiliki pengaruh besar, semisal Fazlur Rahman. Lihat: Abdullah Saeed, The Quran: An Introduction (New York: Routledge, 2008), 232.

${ }^{5} \mathrm{Hal}$ ini bisa dikaji dalam buku Fazlur Rahman, Islam and Modernity: Transformation of an Intelectual Tradition (Chicago: Chicago University Press, 1982), 8. 
cara pandang baru dalam penafsiran, yang kemudian menginspirasi Saeed untuk menjadi kontekstualis penerus Rahman.

Hal demikian menunjukkan bahwa pondasi dasar pemikiran yang diserap Saeed dari Rahman kemudian ditekuni secara serius olehnya untuk menghasilkan sebuah kerangka atau lagkah-langkah yang kokrit, sehingga nampaklah sebuah metodologi yang mapan dalam mengkontekstualisasikan dan menginterpretasikan ayat-ayat Alquran, terutama yang bernuansa etbico-legal yang menjadi sasaran Saeed.

\section{Biografi Singkat Saeed}

Abdullah Saeed merupakan intelektual muslim yang berkebangsaan Oman. Lahir di Maldives pada tanggal 25 September 1964. Perjalanan intelektualnya dimulai dengan belajar Bahasa Arab di Institute of Arabic Language di Saudi Arabia yang kemudian ia mendapat gelar BA pada tahun 1977. Kemudian karir pendidikannya tersebut ia melanjutkan ke program magister dalam bidang applied linguistic dan program doktoral dalam bidang islamic studies di University of Melbourne, Australia.

Menjadi dosen di University of Melbourne pada tahun 1993 pada fakultas Department of Asian Languages and Anthropology. Atas dedikasinya sebagai cendekiawan muslim yang memiliki gagasan besar, akhirnya ia mendapat penghargaan dari Sultan Oman sebagai Professor Bidang Bahasa Arab dan Islamic Studies tahun 2003. Meski demikian ia tetap mendedikasikan dirinya untuk mengabdi dan berkontribusi sebagai direktur dari Center for The Study of Contemporary Islam di Universitas Melbourne.

Di tempatnya mengabdinya itu, Saeed mengajarkan Studi Arab dan Islam pada program S1, S2 dan S3. Di antara matakuliah yang diajarkan diantaranya Great Texts of Islam: Qur'an, Muslim Intellectuals and Modernity, Great Empires of Islamic Civilization, Islamic Banking and Finance, Qur'anic Hermeneutics. Methodologies of Hadith, Methods of Islamic Law, Islam and Human Rights, dan Islam and Muslim in Australia.

Sementara karya-karya Saeed diantaranya disertasi Saeed sendiri Islamic Banking and Interest: A Study of The Probibition of Riba and Its Contemporary Interpretation (1997), Essential Dictionary of Islamic Thought (2001), Muslim Communities in Australia (2002), Freedom of Religion, Apostasy and Islam (2003), Islam in Australia (2003), Islam and Political Legitimacy (2003), Islamic Thought : An 
Introduction (2006), Interpreting the Quran: Towards a Contemporary Approach (2006), The Quran: An Intriduction (2008), dan lain sebagainya. ${ }^{6}$

Yang menarik dari perjalanan intelektual Saeed ialah pergulatannya dalam dua corak alam intelektual antara keilmuan Timur Tengah (lebih tepatnya Arab Saudi yang terkenal pemahaman fundamental) dan keilmuan Barat (tepatnya Australia yang terkenal liberal-rasional). Menjadikannya memiliki kompeten dalam menakar keilmuan Timur dan Barat secara objektif.

\section{Pijakan Awal Interpretasi Saeed}

Tentu tidak mudah bagi Saeed dalam memberikan sebuah konstruksi berpikir umat Islam. Dia tidak serta merta memformulasikan sebuah gagasannya tanpa adanya suatu hal yang menjadi alasan pasti. Pertama, dia berangkat dari pemahamannya tentang wahyu. Konsep wahyu yang dipaparkan oleh Saeed tidak beda jauh dengan pandangan Rahman, terutama pada penekanan aspek psikologis dan historis dari wahyu.

Sebagaimana umat muslim pada umumnya, Saeed mengimani bahwa Alquran adalah wahyu Tuhan yang diturunkan kepada Nabi Muhammad, dan yang ada saat ini (mushaf usmani) tetaplah dinilai otentik. ${ }^{7}$ Namun perlu adanya sebuah rekonstruksi pemahaman bahwa turunnya wahyu itu tidak lepas dari sosio-historis dimana Alquran diwahyukan. Artinya, Alquran tidak turun dalam 'suasana mati' atau hampa budaya, namun ia diwahyukan sebagai respon terhadap kondisi dan permasalahan masyarakat. ${ }^{8}$ Sebab sangat sulit dipahami bagaimana bisa Alquranyang diwahyukan untuk manusia jika tidak bersentuhan langsung dengan manusia dan segala perangkatnya (sosial, budaya, politik, ekonomi, dll). Dengan demikian maka memahami wahyu tidak boleh lepas dari konteks sosio-historis yang melatarinya. ${ }^{9}$

\footnotetext{
${ }^{6}$ Terkait biografi Abdullah Saeed silahkan baca "Curriculum Vitae Professor Abdullah Saeed" yang diakses dari: http://www.abdullahsaeed.org (diakses tanggal 28 Oktober 2018) dan http://asiainstitute.unimelb.edu.au/about/staff/academic/abdullah_saeed/cv (diakses pada tanggal 28 Oktober 2018). Silahkan telusuri pula http://www.law.unimelb.edu.au/index. (diakses 28 Oktober 2018). Alamat web ini merupakan situs resmi Melbourne University. Dan terkait buku-buku Saeed silahkan telusuri http://www.allbookstores.com/AbdullahSaeed/author/1 (diakses tanggal 28 Oktober 2018).

7 Abdullah Saeed, Interpreting the Qur'an: Towards a Contemporary Approach (New York: Routledge, 2006), 5.

${ }^{8}$ Rahman, Islam and Modernity, 6.

9 Abdullah Saeed, "Rethinking 'Revelation' as a Precondition for Reinterpreting the Qur'an: A Qur'anic Perspective," Journal of Qur'anic Studies 1, no. 1 (April 1, 1999): 110, doi:10.3366/jqs.1999.1.1.93.
} 
Sehingga dari situlah dibutuhkan sebuah penginterpretasian yang out of the box dari pemahaman literalis guna mengungkap makna utuh dari apa yang sebenarnya yang ingin disampaikan oleh Alquran. Tidak lain dengan memahami dan mengkaji sosio-historis (konteks) masa pewahyuan tersebut.

Kedua, adanya tradisi klasik terhadap isyarat penafsiran berbasis konteks. Selain pijakannya mengenai wahyu, Saeed juga menyebutkan bahwa sejak masa klasik, isyarat untuk menafsirkan Alquran berbasis konteks sebenarnya sudah tercermin sejak masa lalu (masa awal Alquranditurunkan). Dalam hal ini ia menyebutkan fenomena nasikh mansuk ${ }^{10}$ dan fleksibelitas makna dalam sab'ah abruf. ${ }^{11}$

Adanya fenomena nasikh mansukh menunjukkan bahwa perubahan situasi dan kondisi menyebabkan perubahan etika hukum. ${ }^{12}$ Misalnya, dalam QS. AlBaqarah: 183 yang memerintahkan agar berpuasa sebagaimana puasanya orang dahulu (yakni tidak makan, minum, dan bercampur dengan istri meski pada malam hari), kemudian ayat tersebut di-nasakh oleh QS. Al-Baqarah: 187 yang membolehkan melakukan hubungan suami-istri pada malam hari.

Sedangkan riwayat sab'ah abruf yang disebutkan oleh Nabi Muhammad bahwa Alquran itu diturunkan dalam 'tujuh huruf hal itu dinilai oleh Saeed sebagai penunjukan adanya perbedaan atas tujuh dialek Alquran ${ }^{13}$ Artinya bahwa Nabi telah memungkinkan adanya fleksibilitas kata dalam ayat demi menyesuaikan Alqurandengan kebutuhan saat itu. Disinilah dimungkinkan adanya perbedaan makna yang berimplikasi pada perubahan dan/atau perkembangan hukum. Misalnya, QS. Al-Maidah ayat 6, atas perbedaan bacaan arjulikum atau arjulakum yang persoalan hukumnya apakah dalam berwudhu hendaklah mencuci (menyiram) kaki atau sekedar mengusapinya. ${ }^{14}$ Perbedaan

10 Nasikh mansukh merupakan kajian dalam Ulumul Quran. Nasikh ialah hukum syara' yang menghapus hukum lainnya. Sedangkan mansukh adalah hukum yang dihapuskan oleh hukum lainnya. Pengetahuan tentang nasikh dan mansukh ini mempunyai fungsi bagi para ahli ilmu, terutama fuqaha, ahli tafsir dan ahli ilmu ushul agar pengetahuan hukum tidak kacau balau. Lihat, Manna Khalil Al-Qatthan, Studi Imu-Imu Al-Quran, trans. Mudzakir AS, 16th ed. (Bogor: Pustaka Litera AntarNusa, 2013), 327-29.

${ }^{11}$ Riwayat tentang sab'ab abruf dapat dilihat dalam banyak hadis, salah stau diantaranya yang diriwayatkan oleh Imam Bukhari bahwa Rasulullah bersabda: "Jibril membacakan (AlQuran) kepadaku dengan satu huruf, kemudian berulang kali aku mendesak dan meminta agar huruf itu ditambah, dan dia menambahkannya sampai tujuh huruf (sab'ah ahruf) kepadaku".

${ }^{12}$ Saeed, Interpreting the Qur'an, 85.

${ }^{13}$ Ibid., 70.

14 Yang memiliki pokok persoalan qiraat atas lafadz أرجلكم yang berimplikasi pada persoalan apakah di dalam berwudhu kedua kaki wajib dicuci (disiram) atau sebatas wajib diusapi air saja? Bagi Ibnu Katsir, Hamzah, dan Abu Amr membacanya lam kasrah sehingga menjadi arjulikum yang implikasi hukumnya bahwa dalam wudhu cukup mengusap kaki dengan air (ma'thuf kepada ru'usikum). Sementara bagi Imam Nafi' dan Al-Kisa'i membacanya lam fathah 
dialek seperti inilah yang menjadi alasan bagi Saeed bahwa dimungkinkan adanya variasi dialektika yang berdampak pada perubahan status hukum.

Penerapan kontekstualisasi juga dapat kita lihat dari berbagai kasus pada masa Islam awal (masa sahabat). Salah satu contoh ialah keputusan Umar bin Khattab yang tidak membagi-bagikan tanah (hasil rampasan perang) kepada pasukannya setelah menaklukkan Iraq, melainkan tanah tersebut tetap diberikan kepada penduduk setempat. Tentu hal ini menimbulkan kecaman di internal sahabat, sebab keputusan Umar dinilai tidak mengikuti apa yang telah dilakukan Nabi. Sehingga keputusan Umar dianggap 'menyimpang' (menimbulkan kontroversi) pada saat itu. Namun jika ditela'ah lebih lanjut, sebenarnya tindakan Umar tersebut sebagai langkah kontekstualisasi atas kompleksitas persoalan dan hukum syariat. Sebab, jika Umar biarkan membagi-bagikan tanah kepada pasukannya, maka dia khawatir akan terjadi masalah baru yang lebih besar yakni kemiskinan dan kelaparan di daerah yang baru ditaklukkannya. ${ }^{15}$ Dan hal-hal semacam ini banyak sekali terjadi pada masa sahabat dan bahkan di hadapan Nabi sekalipun. Dimana Umar banyak melakukan kontekstualisasi yang kerap keputusannya dianggap kontroversial, namun beralasan kuat.

\section{Prinsip-Prinsip Interpretasi Saeed}

Ada berbagai hal yang harus dijadikan prinsip dalam melakukan sebuah interpretasi menurut Saeed. Diantaranya:

Pertama, adanya kompleksitas makna teks. Menurut Saeed bahwa suatu kata-entah dalam Bahasa Arab ataupun bahasa lain-memiliki kompleksitas atau bahkan tidak pasti. Sebab dalam pengaplikasiannya dalam kehidupan seharihari ragam bentuk kata tersebut tidak dapat diperlakukan secara sama dalam memahaminya. Disamping itu untuk menangkap esensi dari makna tersebut maka seseorang harus menyesuaikan dengan entitas mental penerima pesan (wahyu) serta perkembangan linguistik dan budaya komunitasnya. ${ }^{16}$

Kedua, keseimbangan objektivitas-subjektivitas dalam memberikan batasan teks. Inilah yang membedakan Saeed dengan Rahman. Meskipun dia membangun argumentasi dasarnya dengan pandangan Rahman, namun tidak sepenuhnya Saeed menyetujui pandangan Rahman, termasuk dalam hal

sehingga menjadi arjulakum yang dampak pada hukumnya bahwa hendaklah kaki dicuci atau disirami air (ma'thuf kepada wujubakum).Ibn Mujahid, Kitab As-Sab'ab Fi Al-Qira'at (Mesir: Dar alMa'arif, n.d.), 242.

${ }^{15}$ Muhammad Abid Al-Jabiri, Agama, Negara, Dan Penerapan Syariah (Yogyakarta: Fajar Pustaka, 2001), 45. Lihat juga: Saeed, Interpreting the Qur'an, 91.

${ }^{16}$ Saeed, Interpreting the Qur'an, 104-5. 
subjektivitas-objektivitas penafsiran. Saeed tidak menolak subjektivitas secara total dan tidak pula memustahilkan objektivitas dalam menafsirkan. ${ }^{17}$ Menurutnya, penafsiran bagaimanapun memiliki aturan yang melahirkan batasan-batasan dalam menetukan makna. Disini seorang penafsir tidak boleh bertindak sesuka dan sekehendaknya.

Ketiga, ayat-ayat yang berkaitan ethico-legal sebagai diskursus. Menurut Saeed bahwa kelompok tekstualis dan para mufassir klasik hanya memperlakukan Alquran sebagai kajian bahasa. Buktinya bisa dilihat dari kitab-kitab tafsir klasik yang berfokus pada pemaknaan kata per kata atau gramatikalnya saja, padahal Alquranitu diturunkan sebagai sebuah fenomena yang hidup, resitasi, maupun diskursus. Walaupun tak bisa dipungkiri bahwa Alquran juga merupakan sebuah korpus tertutup yang termaktub dalam mushaf. Artinya, bahwa dibutuhkan balance dimana memposisikan Alquransebagai teks dan sebagai diskursus. ${ }^{18}$

Keempat, menelusuri makna literal teks sebagai langkah awal penafsiran. Hal ini sangat penting bagi Saeed sebab mengetahui asal-muasal dan bentuk aplikatif dari kata tersebut dalam kehidupan masyarakat awal Islam (masa kewahyuan) akan memberikan jalan mudah dalam menelusuri maksud kata sehingga penafsir tidak berpikir 'liar' atau imajinatif. ${ }^{19} \mathrm{Hal}$ ini telah banyak dikaji oleh mufassir klasik yang memang lebih fokus pada tataran lingiustik.

Kelima, pemahaman terhadap konteks sosio-historis. Sebagaimana umumnya telah kita pahami bahwa Alqurantidak turun dalam kehampaan, namun ia diturunkan dalam suatu masa dan peradaban masyarakat (Arab kala itu). Sehingga untuk memaknainya dibutuhkan upaya memahami konteks sosiohistoris di mana Alquran diturunkan (masyarakat Hijaz abad ke-7). ${ }^{20}$ Namun dalam hal ini tidak cukup mengetahui asbabun nuzul suatu ayat, sebab asbabun nu₹ul hanya sebatas memberitakan suatu kasuistik yang mengiringi turunnya ayat, sehingga para mufassir hanya berkutat pada gramatikal, belum menyentuh seutuhnya pada konteks sosial-kesejarahan yang justru lebih penting. ${ }^{21}$

17 Ibid., 107.

${ }^{18}$ Ibid. Gagasan seperti yang demikian sebenarnya telah disampaikan oleh pendahulupendahulu Saeed seperti Nasr Hamid Abu Zayd dan Farid Esack. Silahkan merujuk pada: Nasr Hamid Abu Zayd, Tekstualitas Al-Quran: Kritik. Terhadap Ulum Al-Quran (Yogyakarta: LKiS, 2003). dan Farid Esack, Quran, Liberation, and Pluralism (Oxford: Oneworld, 1997).

${ }^{19}$ Saeed, Interpreting the Qur'an, 114.

${ }^{20}$ Ibid., 115-17.

${ }^{21}$ Pendefinisian-pendefinisan terhadap asbabun nu₹ul yang dilakukan oleh ulama klasik seperti Al-Wahidi dan Az-Zarkasi dinilai oleh Ad-Dahlawi sebagai definisi tradisonalkonvensional. Yang dinamainya sebagai asbabun nuгul skala mikro, sementara ulama mutakbir seperti As-Syatibi dan Ad-Dahlawi bahwa dimensi asbabun nuzul juga harus mencakup skala makro, yakni harus memahami konteks sosial-kultural dan sosial-historis yang melingkupi turunnya ayat atau beberapa ayat tersebut. Jadi bukan hanya dimaknai sebagai sebab 
Menurut Saeed, hal yang perlu ditelusuri oleh seorang penafsir dalam memahami sosio-historis ini meliputi kehidupan Nabi Muhammad secara mendetail baik di Makah maupun di Madinah, spiritualitas di Arab, keadaan sosial, ekonomi, politik, hukum, norma, tatakrama, institusi, dan nilai-nilai yang berlaku di wilayah tersebut (seperti makanan, pakaian, hirarki sosial, interaksi sosial, dan upacara-upacara, serta sebagainya). ${ }^{22}$

Keenam, hirarki nilai dalam teks ethico-legal. Meskipun Rahman terlebih dahulu mempertanyakan tentang hirarki ayat-ayat ethico-legal ini, namun ia sendiri tidak mengidentifikasikan hirarkisitas ayat-ayat ethico-legal (etika-hukum). ${ }^{23}$ Karenanya, perumusan hirarki ethico-legal oleh Saeed ini merupakan sumbangan besar Saeed terhadap double movement-nya Rahman. Saeed mengidentifikasikan hirarkisitas ayat-ayat ethico-legal sebagai berikut:

1) Obligatory values (nilai-nilai yang bersifat wajib)

Nilai-nilai ini bekaitan dengan ayat-ayat yang bersifat kewajiban (sifatnya tetap dan tidak dapat diotak-atik). Misalnya ayat-ayat keimanan (Allah itu Esa, tidak ada sesembahan selain Allah, dan sebagainya), peribadatan (shalat, puasa, haji, berdzikir, dan sebagai), yang haram dan halal (yang secara tegas disebutkan dalam Alquran $)^{24}$ kesemuanya bersifat obligator alias bersifat tetap. Ayat-ayat ini terulang berkali-kali dalam Alqurandan tidak akan berubah meski berada di mana pun (bersifat universal).

2) Fundamental values (nilai-nilai fundamental)

Menurut Saeed bahwa nilai-nilai fundamental adalah nilai-nilai yang mendapat penekanan berulang-ulang dalam Alquran yang juga disertai bukti teks yang kuat yang mengindikasikan bahwa ayat-ayat tersebut termasuk bagian ajaran fundamental (dasar-dasar) Alquran. Hal ini menurut Saeed menekankan

diturunkannya ayat (beberapa ayat) atau yang mengiringi ayat, tapi juga harus dipahami konteks yang ada pada waktu itu (sosial, budaya, politik, ekonomi, dan lainnya). Pandangan seperti inilah yang kemudian diikuti oleh Fazlur Rahman, Nasr Hamid Abu Zayd, termasuk Abdullah Saeed. Lihat: Fazlur Rahman, Islam, trans. Ahsin Muhammad (Bandung: Pustaka Setia, 1984), 386. Abu Zayd, Tekstualitas Al-Quran: Kritik Terhadap Ulum Al-Quran, 115. Saeed, Interpreting the Qur'an, 117.

22 Saeed, Interpreting the Qur'an, 117.

23 Ibid., 128.

${ }^{24}$ Terkait dengan hal ini, Al-Quran secara tegas menyatakan bahwa ini halal atau itu haram. Untuk sesuatu yang dihalalkan menggunakan redaksi: billun (Al-Maidah [5]: 5), ubilla (AlMaidah [5]: 6), ubillat (Al-Maidah [5]: 1), aballa (Al-Baqarah [2]: 275), ablalna (Al-Ahzab [33]: 50). Sedangkan yang diharamkan menggunakan redaksi: harrama (Al-Baqarah [2]: 173, 275), burrimat (An-Nisa' [4]: 23), barramna (Al-An'am [6]: 146), dan lain sebagainya. 
pada nilai-nilai dasar kemanusiaan, seperti keadilan. ${ }^{25}$ Atau oleh ulama awal seperti Imam As-Syatibi menyebutnya sebagai maqasid asy-syariah (tujuan utama syariah) ${ }^{26}$, dan dalam kajian Fazlur Rahman nilai ini disebutnya sebagai 'prinsip umum' (universal prinsiples).

3) Protectional values (nilai-nilai proteksional)

Nilai proteksional merupakan nilai-nilai yang diturunkan dari nilai-nilai fundamental. Fungsinya tidak lain untuk menjaga keberadaan nilai-nilai fundamental. Misalnya, dalam nilai fundamental (seperti dalam maqasid asysyariah) yakni 'menjaga harta' (bifdz mal), maka nilai proteksionalnya ialah larangan mencuri bagi setiap orang. Oleh sebabnya, karena nilai proteksional ini sebagai turunan dari nilai fundamental, maka sifat unversalitasnya juga tetap berlaku. ${ }^{27}$

4) Implementational values (nilai-nilai implementasional)

Nilai ini merupakan tindakan yang dilakukan untuk menegakkan nilai proteksional. Misalnya terkait larangan mencuri, dimana orang yang ketahuan mencuri, maka ia akan diberlakukan hukuman tertentu sebagai bentuk keadilan. Menurut Saeed, bahwa nilai-nilai implementasional ini tidak berlaku secara universal, sebab banyak hal yang harus diperhatikan, misalnya adanya illat hukum yang berbeda, setting social-culture, fakta sejarah, dan sebagainya. Yang menyebabkan suatu kondisi dimana hukum tersebut terdapat 'pengecualian' dari hukum awal (makna literal teks) karena suatu alasan tertentu.

Seperti contoh, diberlakukannya hukum potong tangan dalam Alquran(Al-Maidah [5]: 38-39) bagi yang terbukti mencuri, selain karena hukum yang memang sudah ada (tradisi) saat itu; juga karena hukum potong tangan dinilai sebagai hukuman paling tepat untuk kondisi saat itu. Namun hal tersebut lagi-lagi tidak bersifat universal, sebab pada masa Umar bin Khattab menjadi khalifah, beliau sesekali hanya menjatuhi hukuman cambuk dan hukuman kurungan bagi pencuri. Sebab, Umar menilai orang yang mencuri (pada masa

${ }^{25}$ Saeed, Interpreting the Qur'an, 132-33.

${ }^{26}$ Maqasid syari'ab menurut Imam As-Syatibi ada lima hal yakni hifdz ad-din (memelihara agama; salah satu dalilnya dalam As-Syura [42]: 13, hifdz an-nafs (memelihara jiwa; Al-Baqarah [2]: 178, hifdz al-'aql (memelihara akal; Thaha [20]: 144, hifdz an-nasab (memelihara keturunan; AnNisa' [4]: 3, hifdz al-mal (memelihara harta; Al-Isra' [17]: 26. Namun hal ini menurut Saeed apa yang disebutnya sebagai nilai-nilai fundamental bisa mengalami perkembangan mengikuti kebutuhan manusia dan perkembangan zaman, misalnya perlindungan kerusakan, perlindungan hak asasi manusia, perlindungan kebebasan beragama, dan lainnya. Lihat: Ibid., 133.

${ }^{27}$ Ibid., 134. 
beliau) karena alasan mendesak; musim paceklik. Sehingga beliau hanya memberlakukan hukum cambuk/kurungan saja. ${ }^{28}$

5) Instructional values (nilai-nilai instruksional)

Nilai-nilai ini berkaitan dengan tindakan yang diambil Alquran tentang suatu persoalan yang (berlaku) khusus pada masa pawahyuan. ${ }^{29}$ Nilai ini bisa berupa larangan atau pun perintah untuk mengatasi permasalahan tertentu pada masa Nabi (masa pewahyuan). Karena nilai-nilai ini berkaitan pada kondisi saat pewahyuan, maka belum tentu bersifat universal.

Saeed menyebutkan bahwa sebagian besar nilai dalam Alquranialah instruksional itu sendiri. Ayat-ayat yang berkaitan dengan nilai instruksional ini paling banyak dan paling beragam ketimbang nilai-nilai sebelumnya. Karena saking banyak dan beragamnya ayat-ayat yang berkaitan dengan instruksional, maka nilai-nilai inilah yang paling sulit dipahami. Misalnya, perintah berpoligami (An-Nisa' [4]: 3), perintah laki-laki menjadi 'pemimpin' bagi perempuan (AnNisa' [4]: 34-35), tidak mejadikan orang kafir sebagai 'kolega' (An-Nisa' [4]: 8990), dan lainnya.

Letak kesulitannya ialah dalam menguhubungkan pesan Alquran(dengan beragam penyampaian dan kompleksitas ayat yang berkaitan) tersebut dengan konteks yang ada pada saat ini. Sehingga Saeed kemudian merumuskan suatu cara agar bisa mengeksplor apakah nilai yang terdapat dalam ayat tersebut bersifat universal atau hanya terbatas pada masa Nabi saja. Yakni dengan mengetahui 1) frekuensi (seberapa sering pesan tersebut disebutkan dalam Alquran), 2) penekanan (menjadi prinsip utama dalam dakwah Nabi), 3) relevansi (sifat universal nilai-nilai tersebut tanpa memperhatikan tempat, waktu, dan kondisi. Artinya bisa diterima jika diterapkan dimana saja, kapan saja, dan kondisi apa saja, tidak sebatas terikat pada masa Nabi).

\section{Model Interpretasi Abdullah Saeed}

Saeed merumuskan langkah kerja dalam menghasilkan sebuah interpretasi yang mapan. Hal yang belum dirincikan oleh Rahman, yang kemudian dijabarkan oleh Saeed bagaimana 'gerak ganda' milik Rahman dapat dipahami dengan baik. Berikut ini empat langkah yang harus dilakukan oleh seorang penafsir dalam menghasilkan suatu interpretasi.

\footnotetext{
${ }^{28}$ Ibid., 136.

${ }^{29}$ Ibid., 137.
} 
48 | AL QUDS : Jurnal Studi Alquran dan Hadis vol. 3, no 1, 2019

\section{Model of Interpretation}

\section{Stage I: Encounter with the world of text}

\section{Stage II: Critical Analysis}

Linguistic

Literary context

Literary form

Parallel texts

Precedents

\section{Stage III: Meaning for the first recipients}

Socio-historical context

Worldview

Nature of the massage: legal, theological, ethical

Message: contextual versus universal

Relationship of the message to the overall message of the Qur'an

\section{Stage IV: Meaning for the present}

Analysis of present context

Present context versus socio historical context

Meaning from first recipients to the present

Message: contextual versus universal

\section{Application today}

Dari empat stage (langkah) interpretasi Saeed, pada stage I dan stage II ini yang meminjam istilah Rahman disebutnya sebagai 'gerak pertama' di mana seorang penafsir harus mampu 'menyelami' berbagai aspek kontekstualisasi yang ada masa pewahyuan. Sementara stage III dan stage IV inilah yang disebut 'gerak kedua' dalam istilah Rahman, dimana penafsir harus mampu membawa pemahaman konteks pada gerak pertama kemudian ditarik pada konteks yang ada saat ini.

Pada stage I dan stage II sebenarnya telah dicover dan banyak dikaji oleh para penafsir klasik (mufassir textualist) dalam tafsir-tafsir klasiknya. Sehingga para 
mufassir modern tidak perlu disibukkan dalam mendapatkannya. Sementara pada stage III dan stage IV ini di mana tugas seorang penafsir modern (progressiveijtihadist) mencurahkan segala kemampuannya dalam mengkontekstualisasikan pada masa saat ini.

Stage I membahas tentang penemuan dunia teks. Dimana mufassir mencari dan mengumpulkan ayat-ayat dalam Alquran terkait permasalahan yang ingin dikaji.

Stage II berkaitan dengan analisis kritis, maksudnya mengkaji makna apa yang diinginkan Alquran tanpa dikaitkan dengan konteks penerima wahyu dan kondisi saat ini (mencari makna 'mentah'nya terlebih dahulu). Hal ini bisa dikaji melalui linguistiknya (penggunaan kata, frase, kalimat dalam ayat tersebut), konteks ayat atau surah (mana yang turun duluan mana yang belakangan, memahami bentuk teks (mengidentifikasi apakah ayat tersebut termasuk dalam teks sejarah, perumpamaan, teologi, hukum, etika, dan sebagainya), memahami keterkaitan teks (mengeksplorasi dan mengumpulkan ayat-ayat terkait dengan tema), dan mengidentifikasi teks yang memiliki kesamaan isi dan maksud).

Stage III berkaitan dengan pengaitan antara makna teks dengan penerima wahyu (nabi Muhammad). Hal ini bisa dilakukan dengan menganalisis kontekstualisasinya (dengan mempertimbangkan sejarah, kehidupan sosial, politik, kebudayaan, dan sebagainya), mempertimbangkan worldview (yakni terkait maqasid syariah apakah teks tersebut membawa nilai-nilai maqasid syariah atau tidak), kemudian mengidentifikasi teks-teks yang menjadi fokus pembahasan, setelah itu menarik 'garis merah' dari teks-teks yang telah teridentifikasi untuk menangkap makna 'alamiah' (makna utuh) dalam Alquran. Selanjutnya mengevaluasi bagaimana teks tersebut diterima oleh komunitas pertama (masa Nabi dan sahabat) sehingga dapat diaplikasikan pada masa itu.

Stage IV ialah merupakan langkah terakhir dalam menginterpretasi, dan langkah ini yang justru begitu penting yang sama sekali tidak tersentuh oleh para mufassir klasik. Langkah ke-IV ini ialah mengaitkan teks dengan konteks masa kini. Hal-hal yang perlu diperhatikan dalam langkah tersebut ialah: menganalisis konteks (masalah dan/atau kebutuhan) pada masa kini yang dianggap relevan dengan pesan-pesan dalam teks. Selanjutnya 'membenturkan' (komparasi) konteks yang ada saat ini dengan konteks sosial-historis di mana teks itu diterima (apakah terdapat nilai-nilai, illat hukum, konteks sosial, politik, budaya yang sama atau tidak), setelah dikomparasikan (ditemukan persamaan atau perbedaan konteksnya) maka bisa ditemukan pengkerucutan terhadap suatu alasan; bagaimana teks itu diterapkan pada masa awal dan bisa diterima masa sekarang, setelah ditemukan suatu alasan yang bulat; maka kembali 'dibenturkan' antara universalitas dan lokalitas pesan teks untuk mengidentifikasi apakah teks 
tersebut bisa diaplikasikan secara universal atau tidak (tentunya dengan mempertimbangkan segala aspek nilai-nilai universal, maqasid syariah, hak asasi, keadilan dan sebagainya).

Dari keseluruhan langkah tersebut, apa yang ditawarkan oleh Saeed, tidak lain untuk menangkap sebuah pesan utuh yang ingin disampaikan oleh Alquran. Sebab memahami Alqurantidak terhenti secara linguistik saja (walaupun menurut Saeed pemahaman linguistik adalah langkah awal dalam menemukan makna dasar), sebaliknya harus dikaji secara mendalam untuk menemukan makna/pemahaman baru sesuai dengan realitas kontemporer.

\section{Kritik Terhadap Heremeneutika Saeed}

Perlu diakui bahwa Saeed merupakan sarjana muslim yang memberikan kontribusi besar dalam mengembangkan sebuah metode interpretasi Alquran terutama dalam melanjutkan pendahulunya, yakni Fazlur Rahman. Namun, sebagaimana pendahulunya (seperti Rahman, Nasr Hamid, dll), Saeed tidak memberikan tafsiran 'mutlak' terhadap keseluruhan ayat-ayat dalam Alquran, hanya sebatas gradualistik pada permasalahan ethico-legal. Hal ini bisa dipahami karena teks-teks yang berkaitan ethico-legal merupakan teks yang paling 'tidak siap' saat dihadapkan pada realitas, padahal dia paling banyak dibutuhkan dalam kehidupan umat. Artinya, Saeed hanya memberikan solusi teoritis-aplikatif pada ayat-ayat tertentu (bagaimana langkah atau metodologis dalam menemukan suatu makna), kurang/tidak menyentuh pada ayat-ayat yang selain ethico-legal.

Selian itu, Saeed nampaknya termasuk orang yang sangat berhati-hati dalam memberikan sebuah interpretasi. Dengan kehati-hatiannya tersebut membuat Saeed terlihat 'kurang berani' menyatakan hasil 'ijtihad'nya. Dalam beberapa hal dalam bukunya, misalnya, tentang warisan. Saeed tidak memberikan jalan formulasi matematis dalam menentukan sikap yang disebutnya sebagai keadilan. Dia hanya berupaya menjelaskan konteks dan peran laki-laki dan perempuan masa lalu (masa di mana wahyu pertama kali diturunkan) kemudian membandingkan dengan konteks masa kini. Berbeda dengan Amina Wadud atau pun Munawir Sjadzali yang secara tegas dalam 'ijtihad' masing-masing. ${ }^{30}$ Namun demikian Saeed telah memberikan suatu pondasi yang kuat dalam melakukan interpretasi yang selama ini dianggap tabu oleh sebagian golongan.

${ }^{30}$ Bandingkan pandangan terkait waris antara Amina Wadud, Qur'an and Woman (New York: Oxford University Press, 1992). Munawir Sjadzali, Kontekstualisasi Ajaram Islam (Jakarta: Paramadina, 1995). 


\section{Kesimpulan}

Berangkat dari kegelisahan intelektual, dimana Alquran secara sewenangwenang ditafsirkan secara tekstual oleh kelompok tekstualis sehingga menjadikan Alquran terasa kaku dan tak sesuai dengan zaman modern (abad 21), maka Saeed-sebagaimana pendahulunya seperti Fazlur Rahman-sebagai intelektual muslim yang memiliki pandangan berkemajuan dan memiliki perhatian besar terhadap Islam, ia berhasil menawarkan jalan alternatif metodologis dalam menginterpretasi Alquran sehingga Alquran tetap menjadi shalih fi kulli zaman wa makan.

Dengan corak tafsir kontekstualnya, Saeed telah berhasil membangun suatu kerangka kerja (kerangka metodologis) dalam mengungkap makna murni dari Alquran yang tentunya dengan beragai hal yang perlu diperdalam oleh seorang mufassir, bukan hanya dari segi linguistik, tapi juga sosio-historis, sosialculture, konteks (saat wahyu pertama diturunkan dan konteks saat ini), serta berbagai perangkat lainnya yang telah dijelaskan di atas.

\section{Bibliografi}

Abu Zayd, Nasr Hamid. Tekstualitas Alquran: Kritik Terbadap Ulum Alquran. Yogyakarta: LKiS, 2003.

Al-Jabiri, Muhammad Abid. Agama, Negara, Dan Penerapan Syariah. Yogyakarta: Fajar Pustaka, 2001.

Al-Qatthan, Manna Khalil. Studi Ilmu-Imu Alquran. Translated by Mudzakir AS. 16th ed. Bogor: Pustaka Litera AntarNusa, 2013.

Choir, Tholhatul. Islam Dalam Berbagai Pembacaan Kontemporer. Yogyakarta: Pustaka Pelajar, 2009.

Esack, Farid. Quran, Liberation, and Pluralism. Oxford: Oneworld, 1997.

Grondin, Jean. Introduction to Philosophical Hermeneutics. New Haven: Yale University Press, 1991.

Mujahid, Ibn. Kitab As-Sab'ab Fi Al-Qira'at. Mesir: Dar al-Ma'arif, n.d.

Rahman, Fazlur. Islam. Translated by Ahsin Muhammad. Bandung: Pustaka Setia, 1984.

-. Islam and Modernity: Transformation of an Intelectual Tradition. Chicago: Chicago University Press, 1982.

Ramadan, Tariq. Western Muslims and The Future of Islam. New York: Oxford University Press, 2004. 
52 | AL QUDS : Jurnal Studi Alquran dan Hadis vol. 3, no 1, 2019

Saeed, Abdullah. Interpreting the Qur'an: Towards a Contemporary Approach. New York: Routledge, 2006.

- Islamic Thought: An Introduction. New York: Routledge, 2006.

- 'Rethinking 'Revelation' as a Precondition for Reinterpreting the Qur'an: A Qur'anic Perspective.” Journal of Qur'anic Studies 1, no. 1 (April 1, 1999): 93-114. doi:10.3366/jqs.1999.1.1.93.

- The Quran: An Introduction. New York: Routledge, 2008.

Sjadzali, Munawir. Kontekstualisasi Ajaram Islam. Jakarta: Paramadina, 1995.

Wadud, Amina. Qur'an and Woman. New York: Oxford University Press, 1992.

http://asiainstitute.unimelb.edu.au/about/staff/academic/abdullah saeed/cv (diakses tanggal 28 Oktober 2018)

http://www.abdullahsaeed.org (diakses tanggal 28 Oktober 2018) 